\title{
In vivo Evaluation of PEGylated 64Cu-liposomes with Theranostic and Radiotherapeutic Potential using Micro PET/CT
}

Petersen, Anncatrine Luisa; Henriksen, Jonas Rosager; Binderup, Tina; Elema, Dennis Ringkjøbing; Rasmussen, Palle Hedengran; Hag, Anne Mette; Kjær, Andreas; Andresen, Thomas Lars

\section{Published in:}

European Journal of Nuclear Medicine and Molecular Imaging

Link to article, DOI:

$10.1007 / \mathrm{s} 00259-015-3272-6$

Publication date:

2016

Document Version

Peer reviewed version

Link back to DTU Orbit

Citation $(A P A)$ :

Petersen, A. L., Henriksen, J. R., Binderup, T., Elema, D6R., Rasmussen, P. H., Hag, A. M., Kjær, A., \& Andresen, T. L. (2016). In vivo Evaluation of PEGylated ${ }^{2}$ Cu-liposomes with Theranostic and Radiotherapeutic Potential using Micro PET/CT. European Journal of Nuclear Medicine and Molecular Imaging, 43(5), 941-952. https://doi.org/10.1007/s00259-015-3272-6

\section{General rights}

Copyright and moral rights for the publications made accessible in the public portal are retained by the authors and/or other copyright owners and it is a condition of accessing publications that users recognise and abide by the legal requirements associated with these rights.

- Users may download and print one copy of any publication from the public portal for the purpose of private study or research.

- You may not further distribute the material or use it for any profit-making activity or commercial gain

- You may freely distribute the URL identifying the publication in the public portal 


\title{
In vivo Evaluation of PEGylated ${ }^{64} \mathrm{Cu}$-liposomes with Theranostic and Radiotherapeutic Potential using Micro PET/CT
}

\begin{abstract}
Anncatrine Luisa Petersen ${ }^{1,2}$, Jonas Rosager Henriksen ${ }^{2,3}$, Tina Binderup ${ }^{4}$, Dennis Ringkjøbing Elema ${ }^{2,5}$, Palle Hedengran Rasmussen ${ }^{5}$, Anne Mette $\mathrm{Hag}^{4}$, Andreas Kjær ${ }^{4}$ and Thomas Lars Andresen ${ }^{1,2, *}$

${ }^{1}$ Technical University of Denmark, Department of Micro- and Nanotechnology, Building 345, 2800 Lyngby, Denmark, ${ }^{2}$ Center for Nanomedicine and Theranostics, Technical University of Denmark, 2800 Lyngby, Denmark; ${ }^{3}$ Technical University of Denmark, Department of Chemistry, Building 206, 2800 Lyngby, Denmark; ${ }^{4}$ Department of Clinical Physiology, Nuclear Medicine \& PET, Rigshospitalet \& Cluster for Molecular Imaging, Faculty of Health Sciences, University of Copenhagen, Blegdamsvej 9, 2100 Copenhagen, Denmark; ${ }^{5}$ Technical University of Denmark, Center for Nuclear Technologies, Hevesy Laboratory, Frederiksborgvej 399, 4000 Roskilde, Denmark.
\end{abstract}

\begin{abstract}
Purpose: To evaluate the potential of PEGylated ${ }^{64} \mathrm{Cu}$-liposomes in clinical diagnostic PET imaging and PEGylated ${ }^{177}$ Lu-liposomes in internal tumor radiotherapy through in vivo characterization and dosimetric analysis in a human xenograft mouse model. Methods: $5 \mathrm{~mol} \%$ and $10 \mathrm{~mol} \%$ PEG liposomes were characterized with respect to size, charge, and ${ }^{64} \mathrm{Cu}$ - and ${ }^{177} \mathrm{Lu}$-loading efficiency. The tumor-imaging potential of ${ }^{64} \mathrm{Cu}-$ loaded liposomes was evaluated using PET-imaging in terms of in vivo biodistribution, tumor accumulation and tumorto-muscle (T/M) ratios. The potential of PEGylated liposomes for diagnostic and therapeutic applications were further evaluated through dosimetry analysis using OLINDA/EXM software. The ${ }^{64} \mathrm{Cu}$-liposomes were used as biological surrogates to estimate the organ and tumor kinetics of ${ }^{177} \mathrm{Lu}$-liposomes. Results: High remote loading efficiency ( $>95 \%$ ) was obtained for both ${ }^{64} \mathrm{Cu}$ and ${ }^{177} \mathrm{Lu}$ radionuclides with PEGylated liposomes and essentially no leakage of the encapsulated radionuclide upon storage and after serum incubation for $24 \mathrm{~h}$ at $37^{\circ} \mathrm{C}$ was observed. The $10 \mathrm{~mol} \%$ PEG liposomes showed highest tumor accumulation $(6.2 \pm 0.2 \% \mathrm{ID} / \mathrm{g})$ compared to 5 mol\% PEG liposomes, which was evaluated by PET imaging. The dosimetry analysis of the ${ }^{64} \mathrm{Cu}-$ liposomes estimated an acceptable total effective dose of $3.3 \cdot 10^{-2} \mathrm{mSv} / \mathrm{MBq}$ for diagnostic imaging in patients. A highabsorbed tumor dose $(114 \mathrm{mGy} / \mathrm{MBq})$ was estimated of the potential radiotherapeutic ${ }^{177} \mathrm{Lu}$-liposomes. Conclusion: The overall preclinical profile of PEGylated ${ }^{64} \mathrm{Cu}$-liposomes showed high potential as a new PET theranostic tracer for imaging in humans. Dosimetry results predicted that a starting administration activity of $200 \mathrm{MBq}$ of ${ }^{64} \mathrm{Cu}$-liposomes should be acceptable in patients. Work is in progress to validate the utility of PEGylated ${ }^{64} \mathrm{Cu}$-liposomes in a clinical research programme. The high-absorbed tumor dose (114 mGy/MBq) estimated for ${ }^{177} \mathrm{Lu}$-liposomes and the preliminary dosimetric studies justify further therapeutic and dosimetry investigations of ${ }^{177} \mathrm{Lu}$-liposomes in animals before potential testing in man.
\end{abstract}

Keywords: Nanoparticle, theranostic, cancer imaging, diagnostic, PET, radiotherapy

\section{Introduction}

The most commonly used PET tracer 2-[ $\left[{ }^{18} \mathrm{~F}\right]$ fluoro2-deoxy-D-glucose (FDG) has become an important tool in diagnostic and prognostic evaluation of cancer patients as well as for monitoring patient response to therapy [1-5]. FDG is mainly suitable for diagnosing tumors with high proliferative activity $[1,6]$ and has limited diagnostic value for several cancer forms such as highly differentiated neuroendocrine (NE) [7,8] and prostatic tumors $[9,10]$. PET isotopes such as ${ }^{18} \mathrm{~F},{ }^{15} \mathrm{O},{ }^{13} \mathrm{~N}$ and ${ }^{11} \mathrm{C}$ have relative short half-lives where only early imaging time-points are possible, leaving biological processes with duration of several hours or days impossible to explore [11]. Tumor imaging using the longer lived PET isotope ${ }^{64} \mathrm{Cu}$, with favorable decay characteristics $(12.7 \mathrm{~h})$, permit studies for as long as $48 \mathrm{~h}$ after injection [12,13]. Isotopes emitting beta-radiation for short-range local radiation therapy can be used for treatment of tumors if the radioisotopes can be targeted specifically to the diseased tissue. NE tumors are known to express specific tumor markers, and approximately $90 \%$ of NE tumors have somatostatin 
receptors over-expressed on tumor cell surfaces [14]. Accordingly, these patients are well suited for peptide receptor radionuclide therapy (PRRT), which has been used for approximately 10 years based on either ${ }^{90} \mathrm{Y}$-DOTATOC or ${ }^{177} \mathrm{Lu}$ DOTATATE [15-17]. The dose-limiting organs for PRRT are the kidney and bladder due to renal excretion of the peptide-based tracer, and tracers limiting this absorbed dose to normal organs are warranted. Another targeting approach is the use of surface modified liposomes with polymers, such as polyethylene glycol (PEG), that strongly reduce reticuloendothelial system (RES) uptake, thereby prolonging liposome circulation half-life, which enhances tumor accumulation by the enhanced permeation and retention (EPR) effect [18].

Several studies on PEGylated liposomes have been performed [18-22] and the optimum level of PEGylation has been extensively discussed [23]. Moreover, characteristics such as tumor size, cancer type and degree of tumor vascularity have a high impact on the degree of tumor extravasation of PEGylated liposomes. A previous study has observed a trend to higher ${ }^{111}$ In-liposome uptake in smaller and more vascular tumors using SPECT imaging [24].

Using our recently reported remote loading method to entrap ${ }^{64} \mathrm{Cu}$ in liposomes [25] we here report a study to evaluate the diagnostic performance of ${ }^{64} \mathrm{Cu}$ loaded PEGylated liposomes in a human xenograft animal model using PET imaging. The study is the first to use PET imaging to investigate the optimal level of PEGylation in liposomes and how this influences the biodistribution and tumor accumulation in tumors of different sizes. The diagnostic potential and safety of ${ }^{64} \mathrm{Cu}$-liposomes as a new PET tracer for clinical use are evaluated through a dosimetry study. In addition, we show the new possibilities with the remote loading method by investigating the therapeutic radionuclide, ${ }^{177} \mathrm{Lu}$, into PEGylated liposomes. A dosimetric analysis is performed to evaluate the potential and safety of the liposomes as carriers of ${ }^{177} \mathrm{Lu}$ radionuclides in internal tumor radiotherapy based on the ${ }^{64} \mathrm{Cu}$-liposome biodistribution data.

\section{Materials and Methods}

Preparation of PEGylated liposomes
PEGylated liposomes consisting of 1,2-distearoylsn-glycero-3-phosphocholine (DSPC), cholesterol (CHOL) and 1,2-distearoyl-sn-glycero-3phosphoethanolamine- $N$-[methoxy (polyethylene glycol)-2000] (DSPE-PEG 2000 ) in the molar ratio 55:40:5 (5 mol\% PEG liposomes) or 50:40:10 (10 mol\% PEG liposomes) were prepared as described previously [25]. The size and zeta-potential of the liposomes were measured on a ZetaPALS instrument (Brookhaven, Holtsville, NY) and the lipid concentrations were determined by ICP-OES (Vista AX, Varian, Palo Alto, CA). The chelating agent, 1,4,7,10-tetra-azacyclododecane-1,4,7,10tetraacetic acid (DOTA, $10 \mathrm{mM}$ ) was trapped within the liposomes during the thin-film hydration and DOTA outside the liposomes was removed by size exclusion chromatography (SEC) (Sephadex G-25) eluted with HEPES buffer $(10 \mathrm{mM}, \mathrm{pH} 7.4,150$ $\mathrm{mM} \mathrm{NaCl}$ ). All lipids were purchased for Avanti Polar Lipids, DOTA was purchased from Macrocyclics, and all other chemicals from Sigma Aldrich.

\section{Cryo-TEM imaging}

Electron microscopy studies were performed using a Philips CM120 BioTWIN transmission electron microscope with a cryo-holder and a cryo-transfer stage. The sample preparation procedure was done as described previously [26]. The sample was prepared with a final lipid concentration of $10 \mathrm{mM}$, and was equilibrated at ambient temperature for 24 $\mathrm{h}$ before vitrification.

\section{${ }^{64}$ Cu production}

Copper-64 was produced on a PETtrace cyclotron (GE Healthcare) equipped with a beamline. The production of ${ }^{64} \mathrm{Cu}$ was carried out via the ${ }^{64} \mathrm{Ni}(\mathrm{p}, \mathrm{n}){ }^{64} \mathrm{Cu}$ nuclear reaction as described previously [25].

\section{${ }^{64} \mathrm{Cu}$ loading into PEGylated liposomes}

The remote loading of ${ }^{64} \mathrm{Cu}$ into PEGylated liposomes has been reported recently [25]. Briefly, $10 \mu \mathrm{L}$ 2-hydroxyquinoline (2HQ) $(0.314 \mathrm{mM})$ in HEPES buffer (10 mM, pH 7.4, $150 \mathrm{mM} \mathrm{NaCl}$ ) was added to a dry vial containing radioactive ${ }^{64} \mathrm{CuCl}_{2}(\sim$ $400 \mathrm{MBq}) .500 \mu \mathrm{L}$ DOTA-containing PEGylated liposomes were added followed by incubation (60 
min). The ${ }^{64} \mathrm{Cu}$-liposomes were purified using a Sephadex G-25 column, eluted with HEPES buffer (10 mM, pH 7.4, $150 \mathrm{mM} \mathrm{NaCl}$ ).

\section{${ }^{177}$ Lu loading into PEGylated liposomes}

${ }^{177} \mathrm{Lu}$-liposomes were prepared and analyzed following the same procedure as the ${ }^{64} \mathrm{Cu}$-liposomes described above. The radioactive ${ }^{177} \mathrm{LuCl}_{3}$ was purchased from Pelkin Elmer.

\section{Liposomal in vitro stability}

Purified ${ }^{64} \mathrm{Cu}$-liposome or ${ }^{177} \mathrm{Lu}$-liposome solutions were tested for radionuclide retention stability by incubating for $24 \mathrm{~h}$ at $37^{\circ} \mathrm{C}$ or $20^{\circ} \mathrm{C}$. The radionuclide retention stability was assayed by measuring the amount of un-encapsulated radionuclides and encapsulated radionuclides by SEC. Additionally stability in human serum of the ${ }^{64} \mathrm{Cu}$-liposome and ${ }^{177} \mathrm{Lu}$-liposome solutions was tested by mixing human serum and liposome solutions $(1: 1)$ at $37^{\circ} \mathrm{C}$ for $24 \mathrm{~h}$ followed by SEC.

\section{Animal models}

Human neuroendocrine tumor cells (NCI-H727) (5 x $10^{6}$ cells) were inoculated in the left and right flank of female NMRI (Naval Medical Research Institute) nude mice $(n=30)$ in a 1:1 mixture of suspended cells and Matrixgel ${ }^{\mathrm{TM}}$ (BD Biosciences, San Jose, CA, USA) and allowed to grow 3 weeks (small tumors : $<0.5 \mathrm{~g} ; n=26$ ) or 4 weeks (large tumors: $>0.5 \mathrm{~g}<1.2 \mathrm{~g} ; n=14)$. All nude mice were purchased from Taconic (Borup, Denmark), and all experimental procedures were conducted with the guidelines set forth by the Danish Ministry of Justice.

\section{Acquisition protocol}

Purified PEGylated ${ }^{64} \mathrm{Cu}$-liposome suspensions were administered intravenously (i.v.) for biodistribution imaging and quantification. All animals were anesthetized with sevofluran and catheterized to ensure proper tail vein injection. The average administered lipid dose levels of both liposome formulations (5 mol\% PEG and $10 \mathrm{~mol} \%$ PEG liposomes) were $10 \mathrm{mg} / \mathrm{kg} \quad(7.8 \quad \pm \quad 1.4$ $\mathrm{MBq} /$ animal) $(n=30)$. After the last PET scan at 24 or $48 \mathrm{~h}$ time-point the mice were sacrificed, and tissues and organs of interest - including the blood, heart, liver, spleen, kidney, lung, small intestine, pancreas, tumors and quadriceps muscle were harvested, and the level of activity in each tissue was measured using a gamma counter. Positron emission tomography (PET) data were acquired on a MicroPET $^{\circledR}$ Focus 120 (Siemens Medical Solutions, Malvern, PA, USA). The voxel size was $0.866 \times 0.866 \times 0.796 \mathrm{~mm}^{3}$ and in the centre field of view the resolution was $1.4 \mathrm{~mm}$. To ensure proper signal-to-noise ratios PET scans were acquired over $20 \mathrm{~min}$ for the first three scans ( $1 \mathrm{~h}, 8 \mathrm{~h}$ and $24 \mathrm{~h}$ ) and $40 \mathrm{~min}$ for the late scan $(48 \mathrm{~h})$. Data were reconstructed with the maximum a posterior (MAP) reconstruction algorithm. For anatomical localization of activity, computer tomography (CT) images were acquired with a MicroCAT ${ }^{\mathbb{R}}$ II system (Siemens Medical solutions, Malvern, PA, USA) with X-ray tube settings of $62 \mathrm{kVp}$ and $500 \mu \mathrm{A}$. CT images were acquired in a 7 -min scan with 360 rotation steps, a $390 \mathrm{~ms}$ exposure time and voxel size of $0.095 \times 0.095 \times 0.095 \mathrm{~mm}^{3}$.

\section{Data analysis}

After data reconstruction PET- and CT images were fused using the Inveon Software (Siemens). The emission scans were corrected for random counts and dead time. The PET- and CT images were used to identify regions of tracer uptake (source organs) and generate regions of interest (ROIs). Those organs that either were identifiable from the CT image or had tracer uptake significantly above background were used as source organs. The organs used were spleen, liver, kidney, left ventricle and tumor. In organs where activity could not be accurately measured on PET images, data from the gamma counter were used. Those organs were the lung, intestine and pancreas due to poor visibility on CT. The blood concentration was measured from the tracer concentration within the left ventricle in the heart [25]. Activity in muscle was quantified by drawing ROIs on the quadriceps muscle, which was well distanced, from the tumor in the flank. The percentage of the injected liposomal dose in blood $\left(\% \mathrm{ID}_{\text {blood }}\right)$, the terminal half-life of the liposomal blood clearance $\left(T_{1 / 2 \beta}\right)$ and the mono-exponential function used for description of the injected dose in blood are defined and calculated according to Equations 1-3 in Appendix B. The percentage of injected dose per gram $(\% \mathrm{ID} / \mathrm{g})$ in the different 
organs and tumors and the standardized uptake value (SUV) are defined and calculated according to Equations 4-5 in Appendix B. The residence time $\left(T_{R}\right)$ from each source organ is used as input in the software OLINDA/EXM [27] and is calculated according to Equation 6 in Appendix B. Human absorbed radiation doses were estimated using the standard male phantom, and mean absorbed tumor doses were estimated using the unit density sphere module. The residence time assigned to the remainder-of-body comprises the full body dose (injected dose) subtracting the source organ doses. This estimate is thus an upper limit since urine excretion was not accounted for.

\section{Statistics}

In vivo results are shown as means \pm standard error of the mean (SEM). The values were analyzed with a one-tail unpaired $t$ test for significant differences (experiments comparing two groups of animals). $P$ values of less than 0.05 were considered significant.

\section{Results}

Characterization of PEGylated liposomes

To evaluate the influence of the degree of PEGylation on tumor accumulation and diagnostic and therapeutic potential, two PEGylated liposome formulations with $5 \mathrm{~mol} \%$ and $10 \mathrm{~mol} \%$ DSPE$\mathrm{PEG}_{2000}$ were prepared. The mean diameter of liposomes with $5 \mathrm{~mol} \%$ PEG was $100 \mathrm{~nm}$ (PDI = $0.025)$ and $116 \mathrm{~nm}(\mathrm{PDI}=0.038)$ for liposomes with $10 \mathrm{~mol} \%$ PEG. The zeta potential was $-16.0 \pm$ $0.4 \mathrm{mV}$ and $-17 \pm 2 \mathrm{mV}$, and the phospholipid concentration was $3.4 \pm 0.1 \mathrm{mM}$ and $3.3 \pm 0.1 \mathrm{mM}$ for $5 \mathrm{~mol} \%$ PEG and $10 \mathrm{~mol} \%$ PEG liposomes, respectively. Fig. 1 shows a cryo-TEM (cryotransmission electron microscopy) image of PEGylated liposomes containing $10 \mathrm{~mol} \%$ DSPE$\mathrm{PEG}_{2000}$, where the dominating sample morphology is unilamellar spherical liposomes with sizes in the range $60-120 \mathrm{~nm} .{ }^{64} \mathrm{Cu}^{2+}$ was remotely loaded into the PEGylated liposomes using 2HQ and DOTA. The ${ }^{64} \mathrm{Cu}$ loading efficiency of the two liposome formulations was comparable $(95 \pm 0.5 \%$ for 5 mol\% PEG liposomes and $96 \pm 2 \%$ for $10 \mathrm{~mol} \%$ PEG liposomes) (Fig. 2A), when liposomes were incubated with ${ }^{64} \mathrm{Cu}-2 \mathrm{HQ}$. When incubating the ${ }^{64} \mathrm{Cu}$-liposomes in human serum at $37^{\circ} \mathrm{C}$ for $24 \mathrm{~h}$, the fraction of radionuclide retained in both
PEGylated liposome formulations was $>99 \%$ (Fig. 2A insert).

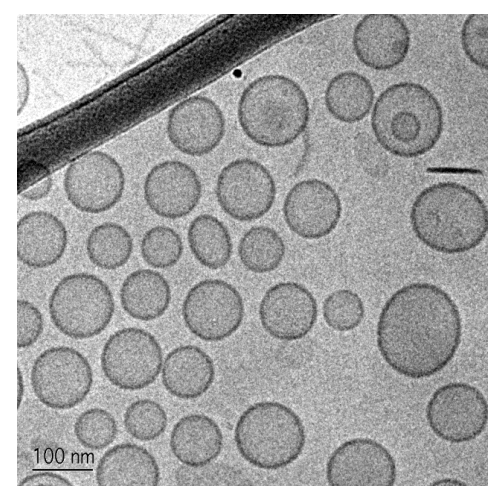

Fig. 1 Cryo-TEM (cryo-transmission electron microscopy) image of $10 \mathrm{~mol} \%$ PEG liposomes consisting of DSPC/CHOL/DSPE-PEG $2000 \quad(50: 40: 10)$ with $10 \mathrm{mM}$ DOTA encapsulated.
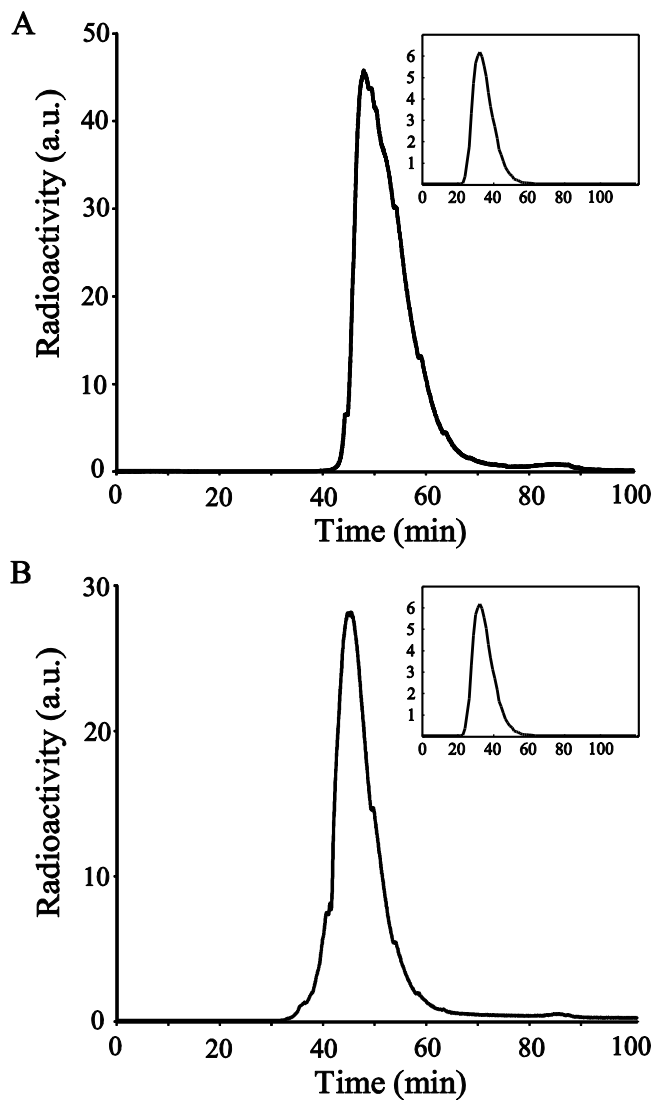

Fig. 2 Size exclusion chromatography (SEC) separation profile of ${ }^{64} \mathrm{Cu}$-liposomes and free ${ }^{64} \mathrm{Cu}$ radionuclide using a Sephadex G-25 column. (A) Preformed liposomes consisting of DSPC/CHOL/DSPE-PEG 2000 (50:40:10) with encapsulated DOTA (10 mM) loaded with ${ }^{64} \mathrm{Cu}$ using 2HQ showed high loading efficiency $(96 \% \pm 2 \%, n=10)$. Insert: A stability test with no leakage of ${ }^{64} \mathrm{Cu}$ from the ${ }^{64} \mathrm{Cu}$ liposomes after incubation in human serum for $24 \mathrm{~h}$ at $37^{\circ} \mathrm{C}$. (B) Preformed liposomes consisting of DSPC/CHOL/DSPE$\mathrm{PEG}_{2000}(50: 40: 10)$ with encapsulated DOTA $(10 \mathrm{mM})$ and loaded with ${ }^{177} \mathrm{Lu}$ using $2 \mathrm{HQ}$ with high loading efficiency $(96.7 \% \pm 0.3 \%, n=4)$. Insert: A stability test of ${ }^{177} \mathrm{Lu}$ loaded liposomes with no leakage $(<1 \%)$ after incubation in human serum for $24 \mathrm{~h}$ at $37^{\circ} \mathrm{C}$. 
Loading efficiency and retention stability of PEGylated ${ }^{177}$ Lu-liposomes

The loading method was also utilized to load ${ }^{177} \mathrm{Lu}^{3+}$ into DOTA-containing liposomes. The ${ }^{177} \mathrm{Lu}$ loading efficiency was similar $(96.7 \% \pm 0.3 \%$, Fig. 2B) to the ${ }^{64} \mathrm{Cu}$ loading into $10 \mathrm{~mol} \%$ PEG liposomes. The ${ }^{177} \mathrm{Lu}$ PEGylated liposomes were stable with minimal leakage $(<1 \%)$ of the encapsulated radionuclide upon storage and after incubation for $24 \mathrm{~h}$ at $37^{\circ} \mathrm{C}$ in serum (Fig. 2B insert).

Impact of PEGylation on liposomes biodistribution and tumor accumulation

The in vivo performance of PEGylated liposomes was evaluated in the human neuroendocrine carcinoma H727-bearing mouse model by PET imaging analysis. The blood clearance profiles (Fig. 3 ) were fitted by a mono-exponential curve and data was treated as described in Appendix B. For 5 mol\% PEG liposomes, $40 \pm 2 \%$ of the injected dose was cleared from the blood within the first hour while the remaining circulating part was cleared with a half-life of $T_{1 / 2 \beta}=10.3 \pm 0.3 \mathrm{~h}$. For $10 \mathrm{~mol} \%$ PEG liposomes a significant lower fraction $(30 \pm$ $2 \%$ ) of the injected dose was initially cleared from the blood compared to the $5 \mathrm{~mol} \%$ PEG liposomes $(P<0.001)$. However, the long circulating parts were cleared at comparable rates for both formulations (10 mol\% PEG liposomes, $T_{1 / 2 \beta}=10.7$ $\pm 1.0 \mathrm{~h})$.

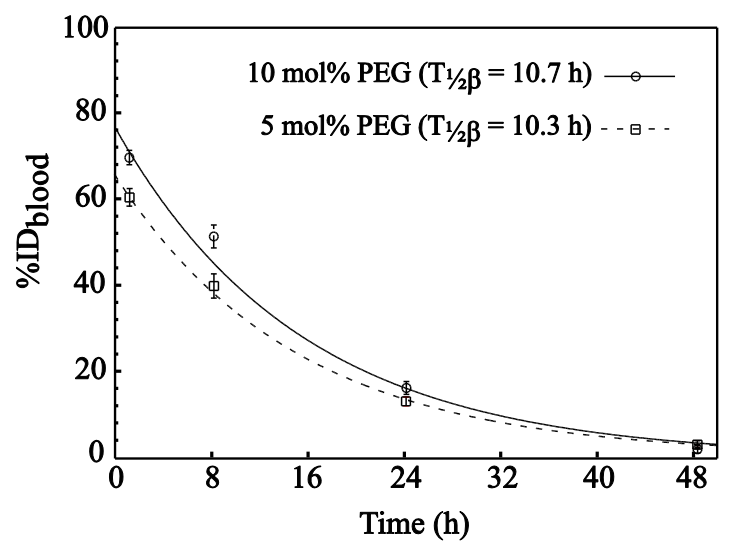

Fig. 3 Blood concentration of $5 \mathrm{~mol} \% \mathrm{PEG}{ }^{64} \mathrm{Cu}$-liposomes $(n=10)$ and $10 \mathrm{~mol} \%$ PEG ${ }^{64} \mathrm{Cu}$-liposomes $(n=10)$ in tumor-bearing mice expressed as percent injected dose (\%ID) as function of time. The blood concentration was estimated from a ROI drawn around the left ventricle on axial PET/CT fusion images. All values are means \pm SEM.
The uptake in the spleen was relatively high after 1 $\mathrm{h}$ as expected and continued to increase throughout the first $24 \mathrm{~h}$ where a peak value for both liposome formulations was reached (Table 1). There was no significant difference in the spleen uptake between the two formulations. In contrast, a significant higher uptake of the $10 \mathrm{~mol} \%$ PEG liposomes in the liver was observed $1 \mathrm{~h}(P=0.006)$ and $8 \mathrm{~h}(P=$ 0.004) (Table 1) compared to $5 \mathrm{~mol} \%$ PEG liposomes. However, at $24 \mathrm{~h}$ and $48 \mathrm{~h}$ the uptake in the liver was comparable for both liposome formulations. There was no significant difference in kidney uptake between the two liposome formulations, and the activity localized in the lungs, pancreas and intestine was low for both liposome formulations (Table 1). The tumor accumulation of $10 \mathrm{~mol} \%$ PEG liposomes was significantly higher compared to $5 \mathrm{~mol} \%$ PEG liposomes at the $24 \mathrm{~h}$ ( $P$ $=0.009)$ and $48 \mathrm{~h}(P=0.017)$ time-points (Table 1$)$. The $\mathrm{T} / \mathrm{M}$ ratio of both liposomal formulations was high at all time-points with a peak value ( $24 \mathrm{~h}$ postinjection) of $11.3 \pm 1.3$ for $5 \mathrm{~mol} \%$ PEG liposomes and $8.9 \pm 0.9$ for $10 \mathrm{~mol} \%$ PEG liposomes, a difference that is borderline significant $(P=0.062)$. Due to higher tumor accumulation of the $10 \mathrm{~mol} \%$ PEG liposomes, the therapeutic potential of this formulation was further evaluated as a function of tumor size.

\section{Impact of tumor size on tumor accumulation}

The tumor accumulation of $10 \mathrm{~mol} \%$ PEG liposomes were evaluated as a function of tumor size (small tumors $(<0.5$ gram; $n=26)$, large tumors $(>0.5<1.2$ gram; $n=14)$ and as a function of time (Fig. 4). A significantly higher liposomal uptake $(\% \mathrm{ID} / \mathrm{g})$ was observed in small tumors at the $24 \mathrm{~h}(P<0.001)$ and $48 \mathrm{~h}(P<0.001)$ time-points compared to large tumors (Fig. 4A). Additionally, a significant higher $\mathrm{T} / \mathrm{M}$ ratio was observed within small tumors at $24 \mathrm{~h}(10.5 \pm 0.7 ; P=0.02)$ and at 48 h $(12.4 \pm 1.0 ; P=0.003)$ compared to large tumors $(7.8 \pm 1.0$ and $8.2 \pm 0.6$ at $24 \mathrm{~h}$ and $48 \mathrm{~h}$ respectively) (Fig. 4B). The tracer accumulation of $10 \mathrm{~mol} \%$ PEG liposomes in small tumors is depicted in Fig. 5. Small tumors were visualized with radioactive hot spots distributed within the whole tumor area, whereas only the rim of larger tumors had high radioactivity (data not shown), as also visualized in a previous study [25]. 

Table 1 Biodistribution and tumor accumulation of H727 Tumor-Bearing Mice after Intravenous Administration of 5 mol\% PEG and $10 \mathrm{~mol} \%$ PEG liposomes

Time after intravenous administration (h)

\begin{tabular}{lcccccccc} 
& \multicolumn{3}{c}{1} & \multicolumn{2}{c}{8} & \multicolumn{2}{c}{4} \\
Organ & $5 \mathrm{~mol} \%$ & $10 \mathrm{~mol} \%$ & $5 \mathrm{~mol} \%$ & $10 \mathrm{~mol} \%$ & $5 \mathrm{~mol} \%$ & $10 \mathrm{~mol} \%$ & $5 \mathrm{~mol} \%$ & $10 \mathrm{~mol} \%$ \\
\hline Spleen & $14.9 \pm 0.6$ & $14.6 \pm 0.7$ & $17.5 \pm 1.0$ & $16.5 \pm 0.8$ & $19.6 \pm 1.0$ & $16.9 \pm 0.7$ & $15.5 \pm 0.7$ & $16.2 \pm 1.0$ \\
Liver & $7.5 \pm 0.4$ & $9.2 \pm 0.5^{*}$ & $10.2 \pm 0.6$ & $13.8 \pm 0.4^{*}$ & $11.5 \pm 0.5$ & $11.7 \pm 0.4$ & $9.6 \pm 0.5$ & $11.4 \pm 0.7$ \\
Lungs $^{\#}$ & $\mathrm{NA}$ & $\mathrm{NA}$ & $\mathrm{NA}$ & $\mathrm{NA}$ & $2.4 \pm 0.3$ & $3.0 \pm 0.8$ & $1.9 \pm 0.1$ & $1.7 \pm 0.1$ \\
Intestine $^{\#}$ & $\mathrm{NA}$ & $\mathrm{NA}$ & $\mathrm{NA}$ & $\mathrm{NA}$ & $6.4 \pm 0.6$ & $5.9 \pm 0.9$ & $5.0 \pm 0.4$ & $6.3 \pm 0.5$ \\
Pancreas $^{\#}$ & $\mathrm{NA}$ & $\mathrm{NA}$ & $\mathrm{NA}$ & $\mathrm{NA}$ & $1.3 \pm 0.2$ & $1.3 \pm 0.5$ & $0.9 \pm 0.1$ & $1.4 \pm 0.3$ \\
Kidneys & $6.9 \pm 0.4$ & $7.9 \pm 0.6$ & $5.8 \pm 0.3$ & $6.4 \pm 0.8$ & $4.8 \pm 0.4$ & $5.3 \pm 0.3$ & $4.3 \pm 0.4$ & $4.9 \pm 0.4$ \\
Tumor & $1.6 \pm 0.1$ & $1.9 \pm 0.1$ & $2.3 \pm 0.2$ & $3.0 \pm 0.2$ & $4.4 \pm 0.4$ & $5.9 \pm 0.2^{*}$ & $4.9 \pm 0.5$ & $6.2 \pm 0.2^{*}$ \\
Muscle & $1.1 \pm 0.2$ & $1.2 \pm 0.1$ & $0.6 \pm 0.1$ & $0.8 \pm 0.1$ & $0.5 \pm 0.1$ & $0.8 \pm 0.1$ & $0.6 \pm 0.1$ & $0.9 \pm 0.2$ \\
T/M & $1.6 \pm 0.2$ & $1.7 \pm 0.1$ & $4.2 \pm 0.4$ & $3.2 \pm 0.25$ & $11.3 \pm 1.2$ & $8.9 \pm 0.9$ & $9.9 \pm 2.3$ & $8.6 \pm 1.4$ \\
SUV & $0.41 \pm 0.04$ & $0.5 \pm 0.1$ & $0.6 \pm 0.1$ & $0.8 \pm 0.2$ & $1.1 \pm 0.2$ & $1.6 \pm 0.3 *$ & $1.3 \pm 0.2$ & $1.7 \pm 0.2 *$
\end{tabular}

Values are represented as $\% \mathrm{ID} / \mathrm{g}$, mean $\pm \operatorname{SEM}(n=10$ at 1,8 and $24 \mathrm{~h}$ and $n=5$ at $48 \mathrm{~h})$

*P< 0.05 versus 5 mol\% PEG liposomes; " tissue measurements from gamma counter; NA: not available; T/M: Tumor-tomuscle; SUV: standardized uptake value

Table 2 Average Organ Residence Times, $T_{R}$, (h)

\begin{tabular}{lcccc}
\hline & \multicolumn{2}{c}{10 mol\% PEG liposomes } & \multicolumn{2}{c}{5 mol\% PEG liposomes } \\
\cline { 2 - 5 } Source organ & ${ }^{64}$ Cu-liposomes & ${ }^{177}$ Lu-liposomes & ${ }^{64}$ Cu-liposomes & $0.8(2.1)$ \\
\hline Kidney & 0.2 & 0.8 & $0.2(0.3)$ & 177 Lu-liposomes \\
Liver & 1.5 & 8.9 & $1.3(2.5)$ & $7.7(21.7)$ \\
Spleen & 0.4 & 2.1 & $0.4(0.8)$ & NA (1.0) \\
Lung & $\mathrm{NA}$ & $\mathrm{NA}$ & $0.4(6.5)$ & $0.7(\mathrm{NA})$ \\
Heart & 0.5 & 0.8 & $0.1(\mathrm{NA})$ & $2.3(\mathrm{NA})$ \\
Tumor & 0.2 & 2.7 & $17.0(15.6)$ & $210.6(192.3)$ \\
REM & 16.8 & 209.9 &
\end{tabular}

Values are averaged over all 10 mice in each groups (10 mol\% and 5 mol\% PEG liposomes)

( ): residence times calculated based on PEGylated liposomal (5.3 mol\% DSPE-PEG ${ }_{2000}$ ) biodistribution data from a clinical study and is an average of 17 patients [28]; NA: not available; REM: Remainder-of-body

\section{Absorbed dose}

The distribution data of $5 \mathrm{~mol} \%$ and $10 \mathrm{~mol} \% \mathrm{PEG}$ liposomes were used for estimating absorbed radiation doses of ${ }^{64} \mathrm{Cu}$-liposomes and ${ }^{177} \mathrm{Lu}-$ liposomes for i.v. injection. For comparison the liposomal biodistribution data from a clinical study [28] was used for estimating the absorbed radiation doses by including the physical decay of ${ }^{64} \mathrm{Cu}$ or ${ }^{177} \mathrm{Lu}$ in determining residence times (Table 2). For both $5 \mathrm{~mol} \%$ and $10 \mathrm{~mol} \% \mathrm{PEG}^{64} \mathrm{Cu}$-liposomes the total effective dose was less than $3.3 \cdot 10^{-2}$ $\mathrm{mSv} / \mathrm{MBq}$, and the organs receiving the highest doses were: spleen, liver, stomach wall, lower large intestine wall, red marrow and lungs (Table 3 in Appendix A), and only limited radiation doses were absorbed in the kidney and bladder for both formulations. 
A

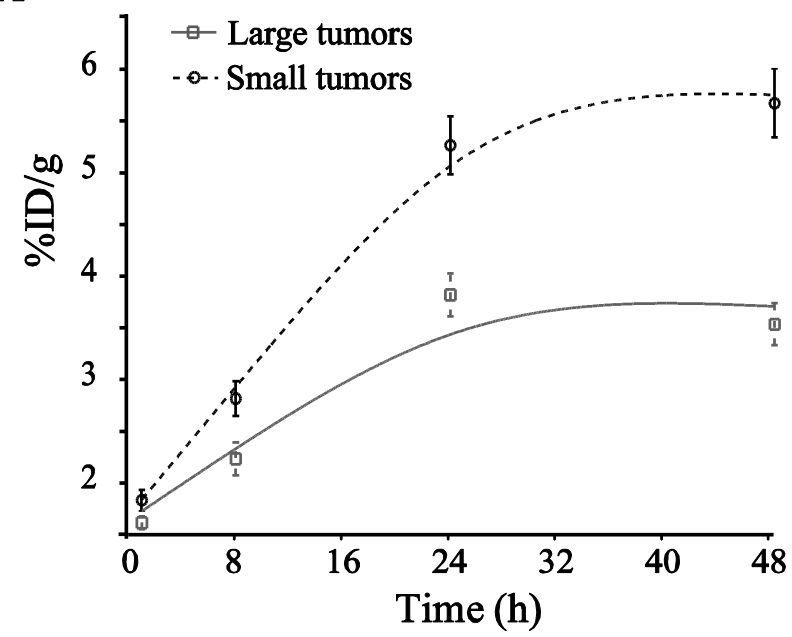

B

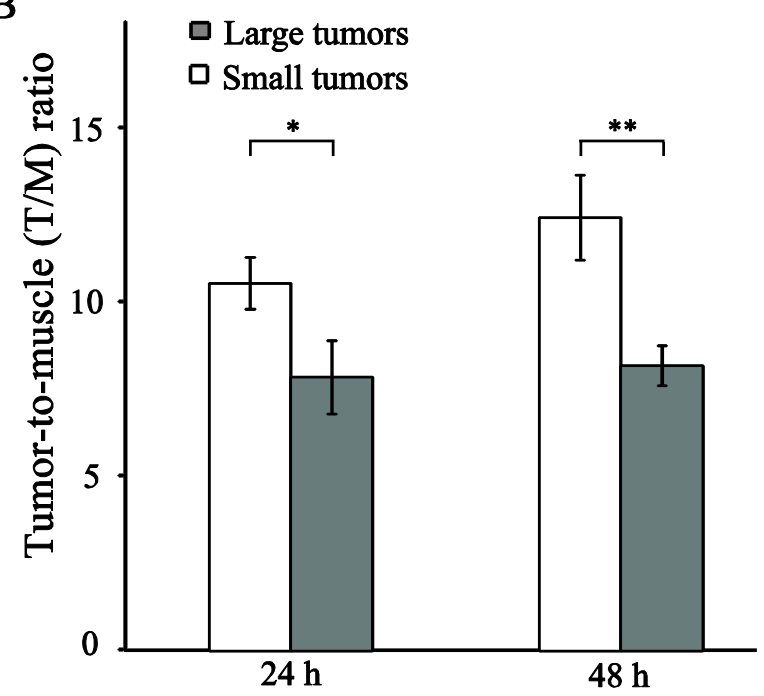

Fig. 4 Tumor accumulation of PEGylated liposomes (10 mol\% PEG) in small tumors ( $<0.5$ gram; $n=26)$ and in large tumors $(>0.5<1.2$ gram; $n=14)$. The tumor accumulation is expressed as \%ID per gram (A) and T/M ratio (B). The values represent the mean \pm SEM. Differences considered to be statistically significant are indicated: $*=P<0.05$ and $* *=P<0.01$.

An administration of $200 \mathrm{MBq}{ }^{64} \mathrm{Cu}$-liposomes yields a total effective dose of $6.6 \mathrm{mSv}$ and $6.5 \mathrm{mSv}$ for the $10 \mathrm{~mol} \%$ PEG and $5 \mathrm{~mol} \%$ PEG ${ }^{64} \mathrm{Cu}$ liposomes, respectively. A dose of $9.2 \mathrm{mSv}$ is obtained (200 MBq administration) when calculation are based on liposomal biodistribution data from a clinical study [28]. A total effective dose less than $2.8 \cdot 10^{-1} \mathrm{mSv} / \mathrm{MBq}$ for both PEGylated ${ }^{177} \mathrm{Lu}$ formulations were estimated (Table 4 in Appendix A), where the organs receiving the highest dose were: spleen, liver, stomach wall, lower large intestine wall, red marrow and lungs for both formulations. The longer circulating 10 mol\% PEG liposomes deposit a higher absorbed dose to the tumor $(114 \mathrm{mGy} / \mathrm{MBq}$ for a 2 -g tumor and $11.5 \mathrm{mGy} / \mathrm{MBq}$ for a $20 \mathrm{-g}$ tumor), compared to $5 \mathrm{~mol} \%$ PEG ${ }^{177} \mathrm{Lu}$-liposomes (96.9 mGy/MBq for a 2-g tumor and 9.8 mGy/MBq for a 20-g tumor) (Table 4 in Appendix A).

\section{Discussion}

In this study we have evaluated the diagnostic potential of PEGylated ${ }^{64} \mathrm{Cu}$-liposomes in a human neuroendocrine carcinoma H727-bearing mouse model using PET imaging, where high $\mathrm{T} / \mathrm{M}$ ratios for optimal tumor visualization were found for both $5 \mathrm{~mol} \%$ and $10 \mathrm{~mol} \%$ PEGylated ${ }^{64} \mathrm{Cu}$-liposomes. The loading method used within this study [25] entraps ${ }^{64} \mathrm{Cu}$ radionuclides in PEGylated liposomes at high concentrations and provides high in vivo stability effective for PET imaging. Imaging agents based on radiolabeled peptides and substrates are of considerable value in nuclear oncology as diagnostic tools e.g. for NE tumors, but exhibit significantly lower in vivo stability and circulation properties compared to the reported ${ }^{64} \mathrm{Cu}$-liposomes. The obtained results within this study look promising when $\% \mathrm{ID} / \mathrm{g}, \mathrm{SUV}$ and $\mathrm{T} / \mathrm{M}$ ratios are compared with results from radiolabeled peptides [11,12]. Imaging agents, such as radiolabeled peptides and ${ }^{18} \mathrm{~F}-\mathrm{FDG}$, are cleared relatively fast from the blood stream through renal clearance resulting in a high degree of radioactivity in the kidney and bladder. During the imaging period this high degree of radioactivity in the kidney and bladder makes diagnosing prostate cancer a challenge. The size and circulation properties of PEGylated liposomes minimize kidney and bladder accumulation. In addition the enhanced in vivo stability, the high tumor accumulation and reduced non-specific binding are all important features making the PEGylated ${ }^{64} \mathrm{Cu}$-liposomes promising as diagnostic PET tracer for a variety of cancer types.

From a drug delivery point of view, the optimal level of PEGylation on different liposome formulations has been extensively discussed [23]. In a study by Chow et al. radiolabeled liposomes ( ${ }^{111}$ In-liposomes) were tested in animals, where effective long-term circulation in the blood and maximum tumor uptake was achieved with $6 \mathrm{~mol} \%$ PEGylated $100 \mathrm{~nm}$ liposomes [22]. 


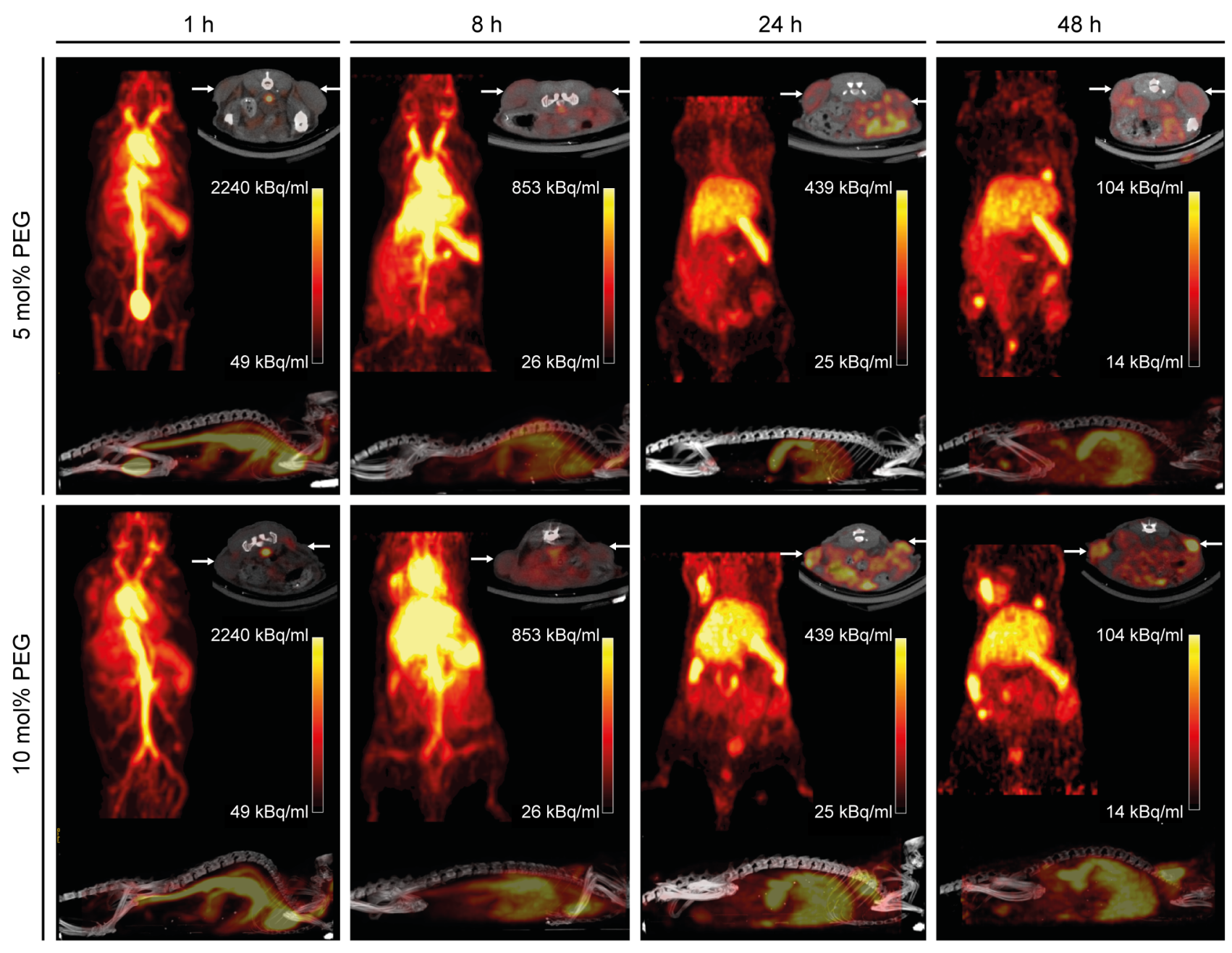

Fig. 5 PET/CT images of tumor accumulation of $5 \mathrm{~mol} \% \mathrm{PEG}$ and $10 \mathrm{~mol} \% \mathrm{PEG}{ }^{64} \mathrm{Cu}$-liposomes in small tumors at 1, 8, 24 and $48 \mathrm{~h}$ after tracer administration. Left: Coronal whole body PET image. Top right: Axial PET/CT-fusion image of tumors. The tumors on right and left flank are marked with arrows. Bottom: Sagital whole body PET/CT-fusion image. The head of the mice are not included in the whole body images.

The measured half-life $\left(T_{1 / 2 \beta}\right)$ reported in the present study was less affected by the PEG level, while the initial clearance of the $5 \mathrm{~mol} \%$ PEG liposomes was significantly higher compared to $10 \mathrm{~mol} \%$ PEG liposomes. Thus a higher fraction of $10 \mathrm{~mol} \% \mathrm{PEG}$ liposomes is expected to be in the circulation. Additionally, we found that inclusion of $10 \mathrm{~mol} \%$ DSPE-PEG $_{2000}$ in the liposomal membrane increased the amount of liposomes found in the tumors when compared to 5 mol\% DSPE-PEG 2000 liposomes. This observation is in accordance with the generally accepted hypothesis that a longer blood circulation half-life results in repeated passages through the tumor site of high concentrations of liposomes, and thereby a greater efficiency of extravasation [23,29]. Furthermore, we observed a trend to higher liposome uptake in smaller tumors per gram tissue as also reported in a previous study [24]. The high levels of liposome uptake measured in smaller tumors may be explained by their higher vascular volumes compared to larger tumors.

The diagnostic safety of ${ }^{64} \mathrm{Cu}$-liposomes as PET tracers was evaluated, and resulted in a total effective dose of less than $3.3 \cdot 10^{-2} \mathrm{mSv} / \mathrm{MBq}$ for both $5 \mathrm{~mol} \%$ and $10 \mathrm{~mol} \%$ PEG liposomes, an acceptable radiation dose in clinical PET imaging according to ICRP guidelines [30]. The combination of PET scanners and computed tomographic (CT) scanners in clinical use provides co-registered images of anatomic and functional information as well as CT-based attenuation correction in a single 
study. In PET/CT scanning procedures, the effective dose is a combination of the dose from the PET and the dose from the CT. Therefore in addition to the radiation dose from the decaying ${ }^{64} \mathrm{Cu}$ radionuclide, the dose from a whole-body CT scanning should be added to the total effective dose, and is normally estimated to be less than $10 \mathrm{mSv}$ [31,32].

A total effective dose less than $20 \mathrm{mSv}$ per patient (both CT and PET) therefore predicts that a start administration activity of $200 \mathrm{MBq}$ of ${ }^{64} \mathrm{Cu}$ liposomes should be acceptable in a clinical study.

The organs receiving the highest doses were spleen, liver, stomach wall, lower large intestine wall, red marrow and lungs, and similar critical organs were identified from the dosimetric analysis of data from a clinical study [28] yielding comparable effective doses. While an evaluation of the absorbed radiation dose based on preclinical studies provides a reasonable guideline, especially for identifying the most critical organs, caution must be exercised in interpreting such approximated absorbed radiation doses. Since variability in calculation approaches (particularly in implementation of the remainder-of-body) can result in erroneous estimated effective doses, direct comparisons between dosimetry studies should be considered carefully. Even though the $10 \mathrm{~mol} \%$ PEG liposomes accumulated in a significant higher degree in the tumors, a less favorable $\mathrm{T} / \mathrm{M}$ ratio was obtained $(8.9 \pm 0.9)$ compared to $5 \mathrm{~mol} \%$ PEG liposomes (11.3 \pm 1.3$) 24 \mathrm{~h}$ after injection. From a diagnostic point of view a high $\mathrm{T} / \mathrm{M}$ ratio together with a low total effective dose is favorable, rendering the $5 \mathrm{~mol} \%$ PEG liposomes most suitable from a diagnostic and safety point of view.

For the development of radiotherapeutic agents knowledge of absorbed radiation doses to various critical organs is crucial for a safe evaluation and understanding of the dose-response relationship of a potential radiotherapeutic agent. For ${ }^{177} \mathrm{Lu}$-liposomes to act as radiotherapeutic agents it is essential that they are highly stable in vivo and carry sufficient amounts of ${ }^{177} \mathrm{Lu}$ radionuclides into the tumor tissue for an effective treatment. One challenge with internal radiation therapy is to deliver the highest possible dose to the tumor while sparing normal organs from damage. Furthermore, to achieve an effective treatment, a $\mathrm{T} / \mathrm{M}$ ratio of at least 3-5 should be reached [33]. We have found that ${ }^{177} \mathrm{Lu}^{3+}$ can be loaded into PEGylated liposomes as efficiently as ${ }^{64} \mathrm{Cu}^{2+}$ (>95\%) similar to a study reporting ${ }^{111} \mathrm{In} /{ }^{177} \mathrm{Lu}$ remote loading $(>90 \%)$ in PEGylated liposomes using oxine [34]. While the ${ }^{177} \mathrm{Lu}$-liposomes in this study showed essentially no leakage when incubated in serum, a significantly lower retention of radionuclides $(83 \%)$ was observed in previous study [34]. This observation may be explained by the higher binding affinity of ${ }^{177} \mathrm{Lu}$-DOTA compared to ${ }^{177}$ Lu-DTPA [35,36].

We foresee that selection of patients suited for ${ }^{177} \mathrm{Lu}$ therapy would require a pretreatment evaluation for which ${ }^{64} \mathrm{Cu}$-liposome PET imaging is ideal. In addition, we have found that it is possible to load ${ }^{64} \mathrm{Cu}$ and ${ }^{177} \mathrm{Lu}$ simultaneously into the PEGylated liposomes (data not shown), thus providing a theranostic potential agent. This doubleloading ${ }^{64} \mathrm{Cu} /{ }^{177} \mathrm{Lu}$ approach could give a simultaneous visualization by PET of ${ }^{177} \mathrm{Lu}$ liposome therapy $\left({ }^{64} \mathrm{Cu} /{ }^{177} \mathrm{Lu}\right.$-liposomes). Whether this PET based imaging approach is superior to SPECT imaging based on pure ${ }^{177} \mathrm{Lu}$-liposomes has yet to be proven, but it should provide superior diagnostic sensitivity [37] and does allow for quantification of lesion uptake by SUV.

The high absorbed doses to the tumors estimated from the dosimetric analysis (114 $\mathrm{mGy} / \mathrm{MBq}$ and $11.5 \mathrm{mGy} / \mathrm{MBq}$ for $2-\mathrm{g}$ and $20-\mathrm{g}$ tumors respectively) suggested that an i.v. administration of ${ }^{177} \mathrm{Lu}$-liposomes could lead to an adequate delivery of therapeutic internal radiation to solids tumors. A significantly lower absorbed dose in tumors $\left(5.74 \cdot 10^{-2} \mathrm{mGy} / \mathrm{MBq}\right.$ for a 20 -g tumor) was obtained in a previous study [34], whereas comparable absorbed doses (9.7 $\mathrm{mGy} / \mathrm{MBq})$ was obtained from administration of ${ }^{177} \mathrm{Lu}$-DOTATATE in patients with metastatic NE tumors [37]. The therapeutic potential of ${ }^{177} \mathrm{Lu}$-liposomes needs to be evaluated further in a tumor-bearing mouse model. One approach to improve the therapeutic performance of ${ }^{177} \mathrm{Lu}$-liposomes could be to utilize liposomes that target specific receptors within the tumor tissue. The liposomes described here can be labeled with ligands on the surface for targetspecific accumulation. A longer tumor residence time together with a shorter blood and liver residence time could possibly improve the doseresponse relationship between myelotoxicity and 
second organ toxicity given a safer internal radiotherapeutic treatment.

\section{Conclusion}

The aim of the study was to investigate the optimal level of PEGylation in liposomes and how this influences the biodistribution and tumor accumulation. A description of the organ and tumor kinetics of PEGylated liposomes was conducted to perform dosimetric calculations on diagnostic $\left({ }^{64} \mathrm{Cu}\right)$ and therapeutic $\left({ }^{177} \mathrm{Lu}\right)$ liposomes. The $10 \mathrm{~mol} \%$ PEG liposomes showed significantly higher tumor accumulation compared to $5 \mathrm{~mol} \%$ PEG liposomes. A larger accumulation of liposomes per tumor weight was observed for small tumors when compared to large tumors. The evaluation of the ${ }^{64} \mathrm{Cu}$-liposomes as diagnostic tracers was successful with clear visualization of the tumors and an acceptable estimated total effective dose to patients of less than $3.3 \cdot 10^{-2} \mathrm{mSv} / \mathrm{MBq}$. Furthermore the dosimetry results predicted a starting administration activity of $200 \mathrm{MBq}$ of ${ }^{64} \mathrm{Cu}$-liposomes should be acceptable in a clinical study. Thus, the overall preclinical profile of ${ }^{64} \mathrm{Cu}$-liposomes strongly indicates that this new PET radiotracer is a very promising candidate in diagnostic cancer imaging in humans. Work is in progress to validate the utility of ${ }^{64} \mathrm{Cu}$-liposomes in a clinical research programme. The ${ }^{64} \mathrm{Cu}$-liposomes have high potential for detection of a variety of malignancies and could be a significant addition to the currently available arsenal for cancer imaging. The remote loading of ${ }^{177} \mathrm{Lu}^{3+}$ into PEGylated liposomes was as efficient as the ${ }^{64} \mathrm{Cu}^{2+}$ remote loading (>95\%), and the ${ }^{177} \mathrm{Lu}$ liposomes have the potential of carrying sufficient amount of ${ }^{177} \mathrm{Lu}$ radionuclides into the tumor tissue for an effective radionuclide treatment. A highabsorbed tumor dose (114 $\mathrm{mGy} / \mathrm{MBq})$ was estimated of the potential radiotherapeutic ${ }^{177} \mathrm{Lu}-$ liposomes. These preliminary dosimetric studies justify further therapeutic and dosimetry evaluation of ${ }^{177} \mathrm{Lu}$-liposomes localized radiotherapy in man.

\section{Compliance with Ethical Standards}

Funding Financial support was kindly provided by the Danish Strategic Research Council (NABIIT) Ref. 2106-07-0033 and the Technical University of Denmark (DTU), the AP Møller Foundation, Danish
National Advanced Technology Foundation, the Novo Nordisk Foundation, Rigshospitalets Research Council, Capital Region of Denmark and the Lundbeck Foundation.

Conflicts of Interest No conflicts of interest.

Ethical Approval All experimental procedures performed in this study involving animals were in accordance with the ethical standards and the guidelines set forth by the Danish Ministry of Justice. This article does not contain any studies with humans performed by any of the authors. 


\section{Appendix A: Tables of Absorbed Radiation Doses}

Table 3. Absorbed Radiation Doses of ${ }^{64} \mathrm{Cu}$-liposomes

\begin{tabular}{|c|c|c|}
\hline Target organ & 10 mol\% liposomes (mSv/MBq) & $5 \mathrm{~mol} \%$ liposomes $(\mathrm{mSv} / \mathrm{MBq})$ \\
\hline Adrenals & $7.85 \times 10^{-5}$ & $7.80 \times 10^{-5}\left(8.31 \times 10^{-5}\right)$ \\
\hline Brain & $5.99 \times 10^{-5}$ & $6.06 \times 10^{-5}\left(5.59 \times 10^{-5}\right)$ \\
\hline Breasts & $1.20 \times 10^{-3}$ & $1.21 \times 10^{-3}\left(1.17 \times 10^{-3}\right)$ \\
\hline Gallbladder wall & 0 & $0(0)$ \\
\hline LLI wall & $3.41 \times 10^{-3}$ & $3.45 \times 10^{-3}\left(3.21 \times 10^{-3}\right)$ \\
\hline Small intestine & $7.37 \times 10^{-5}$ & $7.43 \times 10^{-5}\left(7.12 \times 10^{-5}\right)$ \\
\hline Stomach wall & $3.59 \times 10^{-3}$ & $3.60 \times 10^{-3}\left(3.64 \times 10^{-3}\right)$ \\
\hline ULI wall & $7.37 \times 10^{-5}$ & $7.40 \times 10^{-5}\left(7.19 \times 10^{-5}\right)$ \\
\hline Heart wall & 0 & $0(0)$ \\
\hline Kidneys & $1.62 \times 10^{-4}$ & $1.61 \times 10^{-4}\left(2.34 \times 10^{-4}\right)$ \\
\hline Liver & $3.86 \times 10^{-3}$ & $3.39 \times 10^{-3}\left(6.21 \times 10^{-3}\right)$ \\
\hline Lungs & $3.30 \times 10^{-3}$ & $3.29 \times 10^{-3}\left(1.05 \times 10^{-2}\right)$ \\
\hline Muscle & $6.52 \times 10^{-5}$ & $6.56 \times 10^{-5}\left(6.29 \times 10^{-5}\right)$ \\
\hline Pancreas & $8.32 \times 10^{-5}$ & $8.28 \times 10^{-5}\left(8.89 \times 10^{-5}\right)$ \\
\hline Red marrow & $2.73 \times 10^{-3}$ & $2.74 \times 10^{-3}\left(2.67 \times 10^{-3}\right)$ \\
\hline Osteogenic cells & $5.30 \times 10^{-4}$ & $5.36 \times 10^{-4}\left(5.01 \times 10^{-4}\right)$ \\
\hline Skin & $2.27 \times 10^{-4}$ & $2.29 \times 10^{-4}\left(2.16 \times 10^{-4}\right)$ \\
\hline Spleen & $4.63 \times 10^{-3}$ & $4.63 \times 10^{-3}\left(9.04 \times 10^{-3}\right)$ \\
\hline Testes & 0 & $0(0)$ \\
\hline Thymus & $6.99 \times 10^{-5}$ & $6.95 \times 10^{-5}\left(6.52 \times 10^{-5}\right)$ \\
\hline Thyroid & $1.31 \times 10^{-3}$ & $1.32 \times 10^{-3}\left(1.24 \times 10^{-3}\right)$ \\
\hline Urinary bladder wall & $1.41 \times 10^{-3}$ & $1.42 \times 10^{-3}\left(1.32 \times 10^{-3}\right)$ \\
\hline $\mathrm{ED}_{\mathrm{T}}$ & $3.28 \times 10^{-2}$ & $3.25 \times 10^{-2}\left(4.60 \times 10^{-2}\right)$ \\
\hline
\end{tabular}

LLI wall $=$ lower large intestine wall; $\mathrm{ULI}=$ upper large intestine wall; $\mathrm{ED}_{\mathrm{T}}=$ total effective dose

( ): residence times calculated based on human liposomal (5.3 $\mathrm{mol} \%$ DSPE- $\mathrm{PEG}_{2000}$ ) biodistribution data from a clinical study and is an average of 17 patients [28]. 
Table 4: Absorbed Radiation Doses of ${ }^{177} \mathrm{Lu}$-liposomes calculated from the ${ }^{64} \mathrm{Cu}$-liposome distribution

\begin{tabular}{|c|c|c|}
\hline Target organ & $10 \mathrm{~mol} \%$ liposomes $(\mathrm{mSv} / \mathrm{MBq})$ & $5 \mathrm{~mol} \%$ liposomes $(\mathrm{mSv} / \mathrm{MBq})$ \\
\hline Adrenals & $6.82 \times 10^{-4}$ & $6.83 \times 10^{-4}\left(6.53 \times 10^{-4}\right)$ \\
\hline Brain & $6.53 \times 10^{-4}$ & $6.55 \times 10^{-4}\left(5.99 \times 10^{-4}\right)$ \\
\hline Breasts & $1.28 \times 10^{-2}$ & $1.29 \times 10^{-2}\left(1.19 \times 10^{-4}\right)$ \\
\hline Gallbladder wall & 0 & $0(0)$ \\
\hline LLI wall & $3.26 \times 10^{-2}$ & $3.28 \times 10^{-2}\left(3.00 \times 10^{-2}\right)$ \\
\hline Small intestine & $6.83 \times 10^{-4}$ & $6.85 \times 10^{-4}\left(6.33 \times 10^{-4}\right)$ \\
\hline Stomach wall & $3.25 \times 10^{-2}$ & $3.25 \times 10^{-2}\left(3.07 \times 10^{-2}\right)$ \\
\hline ULI wall & $6.81 \times 10^{-4}$ & $6.83 \times 10^{-4}\left(6.33 \times 10^{-4}\right)$ \\
\hline Heart wall & 0 & $0(0)$ \\
\hline Kidneys & $6.37 \times 10^{-4}$ & $6.37 \times 10^{-4}\left(1.59 \times 10^{-3}\right)$ \\
\hline Liver & $2.14 \times 10^{-2}$ & $1.86 \times 10^{-2}\left(5.11 \times 10^{-2}\right)$ \\
\hline Lungs & $3.19 \times 10^{-2}$ & $3.20 \times 10^{-2}\left(6.99 \times 10^{-2}\right)$ \\
\hline Muscle & $6.59 \times 10^{-4}$ & $6.61 \times 10^{-4}\left(6.09 \times 10^{-4}\right)$ \\
\hline Pancreas & $6.91 \times 10^{-4}$ & $6.92 \times 10^{-4}\left(6.71 \times 10^{-4}\right)$ \\
\hline Red marrow & $2.44 \times 10^{-2}$ & $2.44 \times 10^{-2}\left(2.26 \times 10^{-2}\right)$ \\
\hline Osteogenic cells & $8.21 \times 10^{-3}$ & $8.24 \times 10^{-3}\left(7.56 \times 10^{-3}\right)$ \\
\hline Skin & $2.55 \times 10^{-3}$ & $2.56 \times 10^{-4}\left(2.35 \times 10^{-3}\right)$ \\
\hline Spleen & $2.54 \times 10^{-2}$ & $2.45 \times 10^{-2}\left(9.99 \times 10^{-2}\right)$ \\
\hline Testes & 0 & $0(0)$ \\
\hline Thymus & $6.64 \times 10^{-4}$ & $6.66 \times 10^{-4}\left(6.15 \times 10^{-4}\right)$ \\
\hline Thyroid & $1.33 \times 10^{-2}$ & $1.34 \times 10^{-2}\left(1.22 \times 10^{-2}\right)$ \\
\hline Urinary bladder wall & $1.35 \times 10^{-2}$ & $1.36 \times 10^{-2}\left(1.24 \times 10^{-2}\right)$ \\
\hline $\mathrm{ED}_{\mathrm{T}}$ & $2.79 \times 10^{-1}$ & $2.76 \times 10^{-1}\left(4.08 \times 10^{-1}\right)$ \\
\hline Tumor (mGy/MBq) & $114 * / 11.5 * *$ & $96.9 * / 9.8 * *(\mathrm{NA})$ \\
\hline \multicolumn{3}{|c|}{$\begin{array}{l}\text { LLI wall = lower large intestine wa } \\
* \text { Absorbed dose for a } 2 \text {-g tumor } \\
* * \text { Absorbed dose for a } 20 \text {-g tumor } \\
\mathrm{NA}=\text { not available }\end{array}$} \\
\hline
\end{tabular}

( ): residence times calculated based on human liposomal (5.3 mol\% DSPE-PEG 2000 ) biodistribution data from a clinical study and is an average of 17 patients [28]. 


\section{Appendix B: Equations 1-6}

The percentage of injected dose in blood ( $\left.\% \mathrm{ID}_{\text {blood }}\right)$ was calculated using:

$$
\%^{I} D_{\text {blood }}=\frac{A_{b} \cdot 7.5 \% \cdot m}{D}
$$

where $A_{b}$ is the decay corrected blood activity concentration at time $t$. The animal's blood volume was calculated as $7.5 \%$ of the animal's body weight, $m$. $D$ is the injected activity.

The percentage of injected dose in blood ( $\left.\% \mathrm{ID}_{\text {blood }}\right)$ between $1 \mathrm{~h}$ and $48 \mathrm{~h}$ was fitted to the monoexponential equation:

$\% I D_{\text {blood }}(t)=B \cdot e^{-\beta t}$

where $\beta$ is first-order disposition rate constant or the elimination rate constant, and $B$ represents the fraction of the injected dose, which is cleared from the blood at the disposition rate $\beta$. The fraction of the dose, which is cleared initially, can be estimated by $100 \%-B$. The terminal half-life $\left(T_{1 / 2 \beta}\right)$ of the liposomes was determined using:

$T_{1 / 2 \beta}=\frac{\ln 2}{\beta}$

The data available did not permit accurate estimation of an initial half-life $\left(T_{1 / 2 \alpha}\right)$.

Accumulation in tumor and organs: Liposomal concentrations within each source organ as a function of time were determined from a ROI placed over the entire volume of the organ. The liposomal accumulation in the different organs was expressed as percentage of injected dose per gram (\%ID/g) by using:

$\% I D / g=\frac{A}{D \cdot \rho}$

where $A$ is the decay corrected activity concentration in the tumor and normal organs, and $\rho$ is the organ density and is assumed to be 1 $\mathrm{g} / \mathrm{cm}^{3}$ for all organs and tumors.

The liposomal accumulation in the tumor was further parameterized by the standardized uptake value (SUV) and the tumor-to-muscle (T/M) ratio. The SUV values were calculated using:

$$
S U V=\frac{A \cdot m}{D \cdot \rho}
$$

where $m$ is the animal body weight and $A$ is the decay corrected activity concentration in the tumor. The PET data was not corrected for attenuation, which would give $5-15 \%$ higher ${ }^{64} \mathrm{Cu}$ concentrations than the values provided in this study, depending on the tissue in focus.

For the ${ }^{64} \mathrm{Cu}$-liposome dosimetry study, activity concentration data, which were not corrected for ${ }^{64} \mathrm{Cu}$ radioactive decay $(\hat{A})$, were used to construct activity concentration-time curves for each source organ. For dose calculations the program OLINDA/EXM [38] was used. The residence times $\left(T_{R}\right)$ from each source organs was used as input, and was calculated as:

$$
T_{R}=\frac{V_{\text {organ }}}{D} \cdot \int_{0}^{\infty} \hat{A} d t
$$

where $\hat{A}$ is the activity concentration in the organ as function of time and $V_{\text {organ }}$ is the volume of the source organ. Integration was done using the trapezoidal method to obtain the area up to the last measured activity concentration $\left(\hat{A}^{*}\right)$. An estimate of the long-term tail of the activity concentrationtime curves for the different organs was made by fitting an exponential function $\left(\hat{\mathrm{A}} \sim A \cdot e^{-\beta t}\right)$ to the two last measured points. The area beyond $\hat{A}^{*}$ was then estimated by $\hat{A}^{*} / \beta$. Since steady-state condition for the liposomal concentration within the measured tumor tissue was observed after $24 \mathrm{~h}$ (data not shown), the long-term tail of the activity concentration-time curves was assumed to be governed only by the radionuclide decay. The area beyond $\hat{A}^{*}$ was thus estimated by $\hat{A}^{*} \cdot \frac{T^{1 / 2}}{\ln 2}$, where $T_{1 / 2}$ is the half-life of the radionuclide. 
In the OLINDA/EXM program, activity not assigned to a specific organ must be assigned to the remainder-of-body category. In our calculation, this was estimated as the full injected dose activity received by the body excluding the source organ doses. A separate $T_{R}$ was assigned to the remainderof-body activity concentration-time curve.

For the ${ }^{177}$ Lu-liposome dosimetry study, ${ }^{64} \mathrm{Cu}$-liposomes were used as biological surrogates to study the biodistribution and estimate radiation dosimetry of ${ }^{177}$ Lu-liposomes. Thus, it was assumed that the ${ }^{177} \mathrm{Lu}$-liposomes virtually follow the same biodistribution and pharmacokinetics as the ${ }^{64} \mathrm{Cu}$ liposomes due to the encapsulation of the radionuclides inside the liposomes prohibiting the exchange of the radionuclides with the biological environment. ${ }^{64} \mathrm{Cu}$-liposome activity data for each source organ corrected for ${ }^{64} \mathrm{Cu}$ radioactive decay were multiplied by the physical decay of ${ }^{177} \mathrm{Lu}$ ( $e^{-\ln 2 / T_{1 / 2}}$ ) to obtain estimates for the ${ }^{177} \mathrm{Lu}$ liposome activity concentration in each source organ as a function of time. The $T_{R}$ from each source organ was calculated via equation S6. 


\section{References}

1. Binderup T, Knigge U, Loft A, Federspiel B, Kjaer A. ${ }^{18} \mathrm{~F}$-fluorodeoxyglucose positron emission tomography predicts survival of patients with neuroendocrine tumors. Clin Cancer Res. 2010;16:978-85.

2. Hellwig D, Gröschel A, Graeter TP, Hellwig AP, Nestle U, Schafers HJ, et al. Diagnostic performance and prognostic impact of FDG-PET in suspected recurrence of surgically treated non-small cell lung cancer. Eur J Nucl Med Mol Imaging. 2006;33:1321.

3. Hutchings M, Loft A, Hansen M, Pedersen LM, Buhl T, Jurlander J, et al. FDG-PET after two cycles of chemotherapy predicts treatment failure and progression-free survival in Hodgkin lymphoma. Blood. 2006;107:52-59.

4. Hutchings M, Loft A, Hansen M, Berthelsen AK, Specht L. Clinical impact of FDG-PET/CT in the planning of radiotherapy for early-stage Hodgkin lymphoma. Eur J Haematol. 2007;78:206-12.

5. Torizuka T, Tanizaki Y, Kanno T, Futatsubashi M, Naitou K, Ueda Y, et al. Prognostic value of ${ }^{18} \mathrm{~F}$ FDG PET in patients with head and neck squamous cell cancer. AJR Am J Roentgenol. 2009;192:W156W160.

6. Adams S, Baum R, Rink T, Schumm-Dräger PM, Usadel KH, Hör G. Limited value of fluorine-18 fluorodeoxyglucose positron emission tomography for the imaging of neuroendocrine tumours. Eur $\mathrm{J}$ Nucl Med. 1998;25:79-83.

7. Binderup T, Knigge U, Loft A, Mortensen J, Pfeifer A, Federspiel B, et al. Functional imaging of neuroendocrine tumors: a head-to-head comparison of somatostatin receptor scintigraphy, ${ }^{123}$ I-MIBG scintigraphy, and ${ }^{18}$ F-FDG PET. J Nucl Med. 2010;51:704-12.

8. Miele E, Spinelli GP, Tomao F, Zullo A, De Marinis F, Pasciuti G, et al. Positron emission tomography (PET) radiotracers in oncology - utility of ${ }^{18} \mathrm{~F}$ Fluoro-deoxy-glucose (FDG)-PET in the management of patients with non-small-cell lung cancer (NSCLC). J Exp Clin Canc Res. 2008;27:5261.

9. Ravindra V, Botkin C, Yost P, Osman M. Incidental diagnosis of prostate cancer in FDG PET/CT: An initial experience. J Nucl Med. 2007;48:474P.

10. Schöder H, Larson SM. Positron emission tomography for prostate, bladder, and renal cancer. Semin Nucl Med. 2004;34:274-92.

11. Wadas TJ, Wong EH, Weisman GR, Anderson CJ. Coordinating radiometals of copper, gallium, indium, yttrium and zirconium for PET and SPECT imaging of disease. Chem Rev. 2010;110:28582902.

12. Shokeen M, Anderson CJ. Molecular imaging of cancer with copper-64 radiopharmaceuticals and positron emission tomography (PET). Acc Chem Res 2009;42:832-841.

13. Connett JM, Anderson CJ, Guo LW, Schwarz SW, Zinn KR, Rogers BE, et al. Radioimmunotherapy with a ${ }^{64} \mathrm{Cu}$-labeled monoclonal antibody: A comparison with ${ }^{67} \mathrm{Cu}$. Proc Natl Acad Sci USA. 1996;93:6814-18.

14. Binderup T, Knigge U, Mogensen AM, Hansen CP, Kjaer A. Quantitative gene expression of somatostatin receptors and noradrenaline transporter underlying scintigraphic results in patients with neuroendocrine tumors. Neuroendocrinology. 2008;87:223-32.

15. Pfeifer AK, Gregersen T, Grønbæk H, Hansen CP, Muller-Brand J, Herskind BK, et al. Peptide receptor radionuclide therapy with Y-DOTATOC and (177)Lu-DOTATOC in advanced neuroendocrine tumors: results from a Danish cohort treated in Switzerland. Neuroendocrinology. 2011;93:189-96.

16. Cwikla JB, Sankowski A, Seklecka N, Buscombe JR, Nasierowska-Guttmejer A, Jeziorski KG, et al. Efficacy of radionuclide treatment DOTATATE Y90 in patients with progressive metastatic gastroenteropancreatic neuroendocrine carcinomas (GEP-NETs): a phase II study. Ann Oncol. 2010;21:787-94.

17. Kwekkeboom DJ, Bakker WH, Kam BL, Teunissen JJM, Kooij PPM, de Herder WW, et al. Treatment of patients with gastro-entero-pancreatic (GEP) tumours with the novel radiolabelled somatostatin analogue $\left[{ }^{177} \mathrm{Lu}-\mathrm{DOTA}{ }^{0}, \mathrm{Tyr}^{3}\right]$ octreotate. Eur J Nucl Med. 2003;30:417-22.

18. Gabizon A, Papahadjopoulos D. Liposome formulations with prolonged circulation time in blood and enhanced uptake by tumors. Proc Natl Acad Sci USA. 1988;85:6949-53.

19. Allen TM, Hansen C, Martin F, Redemann C, YauYoung A. Liposomes containing synthetic lipid derivatives of poly(ethylene glycol) show prolonged circulation half-lives in vivo. Biochim Biophys Acta. 1991;1066:29-36.

20. Klibanov AL, Maruyama K, Torchilin VP, Huang L. Amphiphatic polyethyleneglycols effectively prolong the circulation time of liposomes. FEBS Lett. 1990;268:235-37.

21. Lee C-M, Choi Y, Huh EJ, Lee KY, Song H-C, Sun $\mathrm{MJ}$, et al. Polyethylene glycol (PEG) modified ${ }^{99 \mathrm{~m}}$ Tc-HMPAO-liposome for improving blood circulation and biodistribution: The effect of the 
extent of PEGylation. Cancer Biother Radio. 2005;20:620-28.

22. Chow T-H, Lin Y-Y, Hwang J-J, Wang H-E, Tseng Y-L, Pang VF, et al. Therapeutic efficacy evaluation of ${ }^{111}$ In-labeled PEGylated liposomal vinorelbine in murine colon carcinoma with multimodalities of molecular imaging. J Nucl Med. 2009;50:2073-81.

23. Drummond DC, Meyer O, Hong KL, Kirpotin DB, Papahadjopoulos D. Optimizing liposomes for delivery of chemotherapeutic agents to solid tumors. Pharmacol Rev. 1999;51:691-743.

24. Harrington KJ, Rowlinson-Busza G, Syrigos KN, Abra RM, Uster PS, Peters AM, et al. Influence of tumour size on uptake of ${ }^{111}$ In-DTPA-labelled pegylated liposomes in a human tumour xenograft model. Brit J Cancer. 2000;83:684-88.

25. Petersen AL, Binderup T, Rasmussen P, Henriksen JR, Elema DR, Kjær A, et al. ${ }^{64} \mathrm{Cu}$ loaded liposomes as positron emission tomography imaging agents. Biomaterials. 2011;32:2334-41.

26. Henriksen JR, Andresen TL. Thermodynamic profiling of peptide membranes interactions by isothermal titration calorimetry: A search for pores and micelles. Biophys J. 2011;101:100-9.

27. Stabin MG, Sparks RB, Crowe E. OLINDA/EXM: The second-generation personal computer software for internal dose assessment in nuclear medicine. $\mathrm{J}$ Nucl Med. 2005;46:1023-27.

28. Harrington KJ, Mohammadtaghi S, Uster PS, Glass D, Peters AM, Vile RG, et al. Effective targeting of solid tumors in patients with locally advanced cancers by radiolabeled pegylated liposomes. Clin Can Res. 2001;7:243-54.

29. Gabizon A. Stealth liposomes and tumor targeting: One step further in the quest for the magic bullet. Clin Cancer Res. 2001;7:223-25.
30. Vallabhajosula S. Molecular Imaging: Radiopharmaceuticals for PET and SPECT. Springer-Verlag Berlin Heidelberg, 2009.

31. Tonkopi E, Ross AA, MacDonald A. CT dose for whole-body PET/CT examinations. AJR Am J Roentgenol. 2013;201:257-63.

32. Huang B, Law MW, Khong PL. Whole-body PET/CT scanning: estimation of radiation dose and cancer risk. Radiology. 2009;251:166-74.

33. Hamoudeh M, Kamleh MA, Diab R, Fessi H. Radionuclides delivery systems for nuclear imaging and radiotherapy of cancer. Adv Drug deliver Rev. 2008;60:1329-46.

34. Wang H-E, Yu H-M, Lu Y-C, Heish N-N, Tseng Y$\mathrm{L}$, Huang $\mathrm{K}-\mathrm{L}$, et al. Internal radiotherapy and dosimetric study for ${ }^{111} \mathrm{In} /{ }^{177} \mathrm{Lu}$-pegylated liposomes conjugates in tumor-bearing mice. Nucl Instrum Meth A. 2006;569:533-37.

35. Gritmon TF, Goedken MP, Choppin GR. The complexation of lanthanides by aminocarboxylate ligands - I. Stability Constants. J Inorg Nucl Chem. 1977;39:2021-23.

36. Cacheris WP, Nickle SK, Sherry AD. Thermodynamic study of lanthanide complexes of 1,4,7-triazacyclononane-N,N',N', N' ',-tetraacetic acid. Inorg Chem;1987,26:958-960.

37. Wehrmann C, Senftleben S, Zachert C, Müller D, Baum RP. Results of individual patients dosimetry in peptide receptor radionuclide therapy with ${ }^{177} \mathrm{Lu}$ DOTA-TATE and ${ }^{177}$ Lu DOTA-NOC. Canc Biother Rad. 2007;22:406-16.

38. Stabin MG, Sparks RB, Crowe E. OLINDA/EXM: The second-generation personal computer software for internal dose assessment in nuclear medicine. $\mathrm{J}$ Nucl Med. 2005;46:1023-27. 